\title{
Análisis del directorio de la colonia española en México 1991*
}

\author{
Mónica Palma Mora \\ María Magdalena Ordónez \\ INAH
}

Presentación

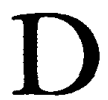

e todos los grupos extranjeros establecidos en México a lo largo de la historia del país como nación políticamente independiente, el español integra, sin lugar a dudas, el grupo que más ha atraído la atención de la historiografia. Una abundante y diversa bibliografia y hemerografia dan cuenta de la presencia española en

* Este trabajo fue financiado por el Ministerio de Trabajo de España y forma parte del proyecto "España en América a través de sus inmigrantes", coordinado por el doctor Álvaro Matute.
México durante el siglo xIX y la primera mitad del xx. No es el caso, sin embargo, de la segunda mitad del presente siglo, particularmente de las tres últimas décadas; los estudios sobre el grupo en este periodo son muy escasos. Este desinterés posiblemente responda a la falta de fuentes disponibles (no se cuenta, por ejemplo, con documentos de archivo).

De este modo, una de las pocas fuentes de información a las que es posible recurrir para el estudio de este grupo, hoy en día, es el Directorio de la Colonia Española. ${ }^{1}$ Desafor-

' Directorio de la Colonia Española, México, s. e., 1991, 435 pp. 
tunadamente no existe ningún relato escrito sobre el origen y motivos para dar a luz esta publicación. Los únicos datos obtenidos fueron proporcionados por la señora Zoila T. González, actualmente directora general del $D i$ rectorio. ${ }^{2}$

Comenzó a editarse aproximadamente en 1955-1956, su fundador fue el señor Domingo Rex Muñoz y de êl sabemos que nació en Lorca, Murcia; que en su país fue maestro de escuela oficial, que era conocedor de literatura y comprendía bien el francés y el portugués. Que ocupó varios cargos en el servicio diplomático español y fue vicecónsul en Beziers, Francia y cónsul interino en Sao Paulo, Brasil. Al estallar la guerra civil (1936) se encontraba precisamente en Sao Paulo y ahí estuvo detenido tres meses por estar a favor del gobierno republicano. Rex Muñoz regresó a España de donde tuvo que emigrar debido a su militancia política, el 1 de noviembre de 1938, por La Junquera hacia Francia, país del cual se vio nuevamente obligado a salir. Rex Muñoz emigró nuevamente a México y salió del puerto de Burdeos el 11 de mayo de 1939 en el vapor De Lasalle. Llegó al puerto de Veracruz el 15 de junio de 1939 , a la edad de 39 años, con recursos económicos propios y en compañía de su esposa Remedios Pellón Ballesteros de 38 años de edad, y de sus hijos Domingo de 15 años, Ricardo de 13, Fernando de 8 y Rosa

\footnotetext{
2 Entrevista a la señora Zoila T. González, directora general del Directorio de la Colonia Española en México, por Mónica Palma y Magdalena Ordóñez en la ciudad de México, mayo de 1991.
}

Rex Pellón de 4 años, todos ellos estudiantes. ${ }^{3}$

Al principio de su estancia en el país, relató la señora González, atravesó "por penalidades económicas", posteriormente su situación mejoró. La informante agregó que "fue un hombre capaz y apolítico desde que pisó suelo mexicano" ${ }^{n 4}$ y destacó que se trataba de un personaje al cual "no se le ha hecho justicia". Por este motivo narró lo siguiente:

Al iniciarse la década de los cincuenta, Rex Muñoz inició un programa de radio de índole cultural titulado México y España, el cual tuvo dos pa. trocinadores: el primero, don Paulino Cato, dueño de la Ferretería Cato, y el segundo, Aerovías Gest. El programa duró alrededor de dos años porque, en 1953, Rex Muñoz decidió transmitirlo por televisión. Con este fin fundó la empresa Filmorex cuyo patrocinador fue Pablo Diez, dueño de la Cervecería Modelo y amigo de Rex Muñoz. Con el nombre de México y España el programa versó sobre los aspectos culturales y socioeconómicos de ambos países y se transmitió durante 17 años.

En 1955, Rex Muñoz emprendió una nueva empresa: el Directorio de la Colonia Española. Esta publicación tuvo como objetivo ser un medio de comunicación y de enlace entre los españoles residentes en el país, unificarlos, ya que la comunidad se encontraba sumamente dividida por cuestiones políticas (unos eran partidarios del go-

${ }^{3}$ Archivo del Comité Técnico de Ayuda a los Republicanos Españoles, caja núm. 053, expediente núm. 2694.

${ }_{4}$ Entrevista a la señora Zoila T. González, op. cit.

Mónica palma, Magdalena ORdóñez 
bierno franquista, otros del gobierno republicano exiliado en México). Pero también tuvo como objetivo ser una fuente de información de "lo más selecto de la comunidad española". La primera edición -en 1955-constó de 3000 ejemplares. Sus fuentes de información fueron las distintas asociaciones españolas establecidas en el país en ese entonces, tanto de los antiguos residentes como de los refugiados, el Consulado y los mismos españoles a título individual. Desde su fundación, se edita anualmente.

En 1960 tuvo lugar la depuración de los datos contenidos en el Directorio con el objeto de actualizarlo y de que incluyera principalmente información sobre los hombres de negocios.

En 1975, aproximadamente, el señor Rex Muñoz se retiró de las actividades que hasta ese momento venía realizando. La señora González quien, por otro lado, fue una colaboradora cercana a este personaje y cofundadora de las empresas Filmorex y del Directorio, compró la totalidad de las acciones de la publicación. Fue la única dueña hasta 1985, año en que, a raíz del terremoto, se perdió parte de la documentación la cual, sin embargo, logró recuperarse, pues la señora conservaba una copia en su domicilio.

La publicación enfrentaba además problemas financieros. Por este motivo estuvo a punto de dejar de editarse. Para poder continuar, la señora González se asoció con Carlos Casa. nueva Varas que actualmente funge como presidente del Directorio. Su cargo es más bien honorífico porque, según dijo la informante, los verdaderos responsables son ella y un sobrino suyo.
Actualmente el Directorio tiene como objetivo ser un medio de información "de y para lo más selecto de la colonia española". Su intención es informar sobre los hombres de negocios, sobre sus relaciones, en suma, "mostrar el poder económico de los españoles". Por lo mismo, no es una publicación de carácter popular ni comercial; no se vende porque maneja "datos rigurosos, confidenciales que se pueden prestar a manipulaciones, $o$ bien a cometer delitos".

Es una publicación destinada a las "empresas económicamente más poderosas, mexicanas y españolas", 5 establecidas en el país y, por consiguiente, a los dueños, socios o altos ejecutivos de las mismas. Por este motivo, los responsables del Directorio son los que deciden a quiénes incluir. En general se distribuye entre la población registrada y el tiraje actual es de 8000 ejemplares. Los datos han dejado de provenir de las asociaciones y del Consulado; por el contrario, éstas yel Sanatorio Español se nutren o recurren al Directorio. (La información se actualiza en forma directa, vía telefónica.) Su medio de financiamiento es la publicidad, y sus patrocinadores son empresas industriales, comerciales e instituciones financieras.

En un principio y durante varios años, el Directorio contuvo información sobre los españoles establecidos en el interior del país, pero debido a que, en los últimos años, el costo de la edición es muy elevado, esta información ha desaparecido.

5 Ibid. 


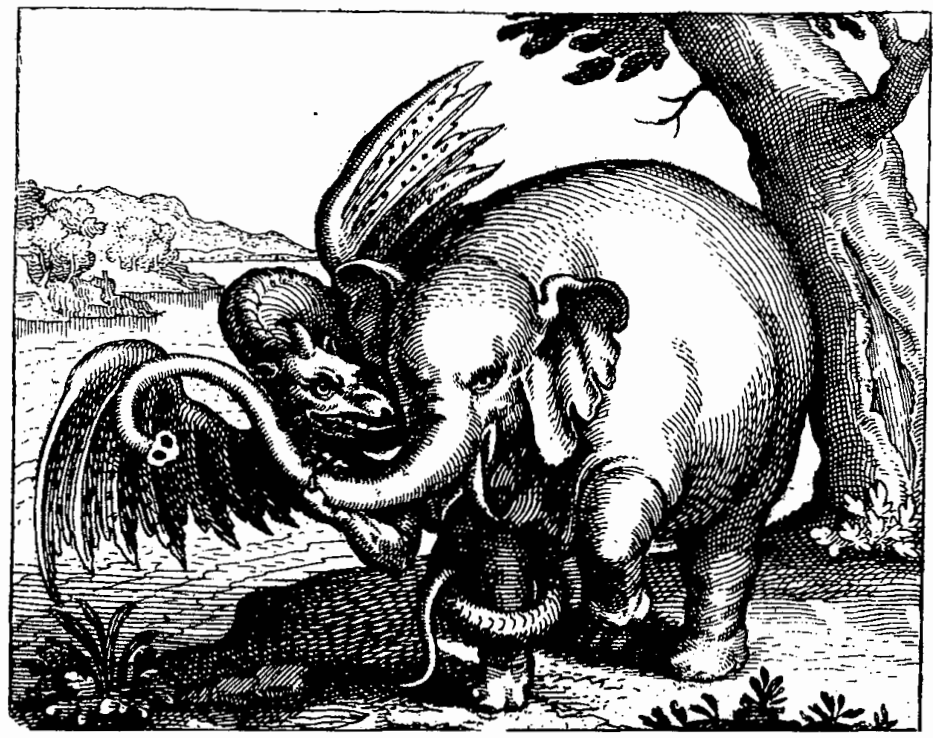

El Directorio de 1991 no incluye, salvo en ciertos casos, datos sobre los españoles radicados en el interior de la república; se ciñe únicamente al Distrito Federal y al Estado de México.

\section{ESTRUCTURA DEL DIRECTORIO}

Esta publicación plantea en el prólogo "que ha hecho de sus servicios de consultoría social, financiera e industrial, el instrumento informático idóneo del medio hispano". Y agrega que,

los objetivos de este anuario han logra do los propósitos de su creación: situar se como un medio de comunicación en el ámbito de la comunidad española en México, ya que es una publicación de consulta obligada entre las institucio. nes nacionales que tienen relación con la colectividad española. 6

El cargo de presidente honorario recae en el señor Carlos Casanueva Varas, la directora general es la señora Zoila T. González A. y el gerente gene. ral es el señor José Francisco González C. quienes, según se dice en el mismo prólogo, en colaboración de un equipo, cotejan con interés los nombres y referencias de esta fuente. ${ }^{7}$

El Directorio se divide de la siguiente manera:

1) Directorio de la Embajada de España, Dependencias y Consulados en México.

6 Directorio de la Colonia Española, México, 1991, p. 25.

${ }^{7}$ Ibid. 
2) Directiva de la Sociedad Española de Beneficencia.

3) Directorio y Cuerpo Médico del Hospital Español (incluye domicilios y consultorios particulares).

4) Directorio alfabético de la Colonia Española en México.

5) Directorio industrial, comercial $\mathrm{y}$ financiero de las diversas actividades económicas y empresas en que se ubica este grupo.

\section{PERFIL SOCIOECONÓMICO DE LA} POBLACIÓN ESPAÑOLA REGISTRADA EN EL DIRECTORIO

Esta publicación comprende a 6541 individuos en total, de los cuales proporciona los siguientes datos: nombre, domicilio particular, domicilio y denominación de la empresa o lugar en donde labora, la ocupación que realiza, nombre del cónyuge e hijos.

De estas seis variables, únicamente las dos primeras (nombre y domicilio particular) son uniformes, es decir, se registran en todos los casos, salvo contadas excepciones. En cambio, las otras cuatro variables no son continuas, sino muy desiguales, no siempre aparece el domicilio del lugar de trabajo, la ocupación, el nombre del cónyuge y los hijos. Del mismo modo, tampoco se precisa el cargo que ocupa la persona en la empresa o empleo registrado. Por este motivo, esta variable no se considera en este perfil. En cambio, en las otras cinco variables los datos aparecen claramente especificados.

Las características que presenta la población española incluida en el $D t$ - rectorio se obtuvieron de la siguiente manera:

En primer lugar, con el objeto de clarificar si se trata de una población mayoritariamente masculina o femenina, del nombre del socio se obtuvo el sexo del mismo. En segundo lugar, el nombre del cónyuge, en su caso, nos permitió detectar el estado civil. En tercer lugar, del total de individuos que consignan tener descendientes, se obtuvo lo que en este trabajo se ha titulado Promedio de hijos por familia; esta variable permite observar si se trata de un grupo integrado por familias pequeñas o numerosas. Asimismo, el número de descendientes reveló un universo más amplio de personas de ascendencia española registrada en el Directorio.

La variable ocupación en buena medida es indicativa de la forma como este grupo está integrado a la economía nacional y revela su estatus dentro de la estratificación social, aspecto que es posible observar también al analizar la variable domicilio particular y que, en el presente escrito, hemos titulado Lugar de residencia. Esta información muestra el tipo de colonias en donde habita este grupo.

Por otra parte, cabe destacar que las cifras y porcentajes que a continuación se presentan están en relación siempre, en cada variable en particular, con el total de casos que contienen la información correspondiente.

\section{Sexo}

De los 6541 casos registrados en esta fuente, son: 


$\begin{array}{lrr} & \text { Total } & \% \\ \text { Hombres } & 6374 & 97 \\ \text { Mujeres } & 167 & 3 \\ & & \\ \text { Estado civil } & & \\ \text { Hombres } & 6374 & 100 \\ \text { Casados } & 3256 & 51 \\ \text { Viudos } & 2 & 0 \\ \text { No registran } & & \\ \quad \text { estado civil } & 3116 & 49 \\ & & \\ \text { Mujeres } & 167 & 100 \\ \text { Casadas } & 10 & 6 \\ \text { Viudas } & 50 & 30 \\ \text { No registran } & & \\ \quad \text { estado civil } & 107 & 64\end{array}$

Es evidente, por los datos antes anotados, que el sexo predominante en la población registrada en esta fuente, es el masculino, que equivale al $97 \%$ del total de los casos; en cambio el sexo femenino es sumamente minoritario, a éste corresponde únicamente el 3\% de los casos. Estos datos, sin embargo, no reflejan por sí solos de un modo cabal la composición por sexo de esta población española, ya que, al confrontarlos con los datos contenidos en la variable estado civil, el porcentaje correspondiente al sexo femenino aumenta. Es decir, si del total de hombres registrados (6374) se toma en cuenta que 3256 están casados, quiere decir que existe un número igual de esposas o de mujeres casadas, buena parte de las cuales seguramente son de ascendencia española y que, sumadas a las 167 de antemano registradas, dan un total de 3423 mujeres, esto es el $52 \%$ del total de casos registrados por el Directorio. De este modo es posible plantear que este grupo de residentes españoles se compone numéricamente en forma casi similar tanto de hombres como de mujeres, y no exclusivamente de hombres como pudiera parecer en un primer momento, por lo menos la cifra de hombres casados revela una mayor presencia femenina a la inicialmente planteada.

Por otro lado, es de llamar la atención que el Directorio no considere el estado civil de la mayor parte de las 167 mujeres registradas, seguramente porque se trata de mujeres solteras, pero también cabe la posibilidad de que varias de ellas sean divorciadas, estado civil que no es considerado por esta fuente en ningún caso. De estas 167 mujeres destaca que 50 de ellas sean viudas y sólo un $6 \%$ sean casadas, este último porcentaje seguramente aumentaría si se supiera con certeza la nacionalidad de las 3256 esposas antes señaladas (véanse gráficas de la núm. 1 a la 3).

\section{Promedio de hijos por familia}

El Directorio registra esta variable en 2067 casos (correspondiente al 32\% del total) y no la consigna en 4474 casos (es decir el $68 \%$ del total). Esta sensible falta de información (al igual que en el caso del estado civil) puede responder a varias razones. Una de ellas quizá es que esta población efectivamente, en su mayor parte, carece de descendientes; la otra, posiblemente la más acertada, es que el Directorio no contenga datos actualizados.

De este modo, de los 2067 casos que contiene esta variable, se obtuvie. ron los siguientes datos: 


$\begin{array}{lrr}\text { Familias con: } & \text { Total } & \% \\ & 2067 & 100 \\ \text { Un hijo } & 323 & 16 \\ \text { Dos hijos } & 534 & 26 \\ \text { Tres hijos } & 437 & 21 \\ \text { Cuatro hijos } & 348 & 17 \\ \text { Cinco hijos } & 231 & 11 \\ \text { Seis hijos } & 90 & 4 \\ \text { Siete hijos } & 60 & 3 \\ \text { Ocho hijos } & 24 & 1 \\ \text { Nueve hijos } & 13 & 0.6 \\ \text { Diez hijos } & 7 & 0.3\end{array}$

Como se puede observar, este grupo se integra, en su mayoría, por familias pequeñas; el porcentaje más alto corresponde al de las familias compuestas por dos hijos, no obstante la tasa promedio de hijos en general de las familias que registran esta variable es de $3.18 \%$. Estos datos permiten plantear lo siguiente:

Si bien es cierto que esta pobla. ción se compone mayoritariamente de familias pequeñas, se observa también una tendencia a tener una prole numerosa, la cual en cierta medida se confirma al examinar los promedios correspondientes a las familias integradas por tres y cuatro hijos, éstas representan el 21 y $17 \%$, respectivamente. Claro está, estos datos podrían modificarse si la variable descendencia estuviese registrada en todos los casos.

Por otro lado, la cifra total de hijos asciende a 6588 , los que sumados a los 6541 casos ya consignados, dan un total de 13029 personas, cifra que bien puede aumentar aproximadamente a 15000 si se considera que parte de las esposas registradas en esta fuente son españolas, es decir, el Directorio incluye un universo mucho más amplio de individuos de ascendencia española. Conjuntamente se puede plantear por los datos antes anotados, que este grupo presenta una significativa tendencia a integrarse familiarmente (véase la gráfica núm. 4).

\section{Ocupaciones y profesiones}

El Directorio, como se dijo antes, desafortunadamente no consigna en todos los casos esta variable y tampoco contiene una clasificación propia de las actividades ocupacionales de sus so. cios, sino por el contrario, presenta una gran diversidad. Por lo tanto, en este trabajo únicamente se consideraron los casos en que a parece esta variable y se tuvo que elaborar una clasificación de las ocupaciones y profesiones más representativas, en donde quedaron incluidas todas las actividades registradas, y es la siguiente:

$\begin{array}{lrr} & \text { Total } & \% \\ \text { Registran } & & \\ \quad \text { ocupación } & 3090 & 47 \\ \text { No registran } & 3451 & 53 \\ \text { Actividades } & & \\ \text { primarias } & 15 & 0.4^{\mathbf{a}} \\ \text { Agricultores } & & \\ \text { Avicultores } & 5 & \\ \text { Floricultores } & 1 & \\ \text { Ganaderos } & 2 & \\ \text { Piscicultores } & 4 & \\ \text { Mineros } & 1 & \end{array}$


Actividades

secundarias

Contratistas $^{b}$

Empresarios

Fabricantes

Industriales

Inversionistas y propie-

tarios (de empresas

industriales)

Técnicos

\section{Actividades}

terciarias

Comercio

Comerciantes

en gral.

Agente

Agente viajero

Valuador

Vendedor

Finanzas

Banqueros

Ocupaciones y

profesiones

liberales

Arquitectos

Abogados

Catedráticos

Científicos

Cinematografistas

Contadores públicos

Economistas

Editores

Escritores

Fotógrafos

Impresores

Ingeniẹro civil

$\begin{array}{rr}625 & 20^{a} \\ 10 & 2^{c} \\ 23 & 4 \\ 35 & 6 \\ 481 & 78 \\ 11 & 2\end{array}$

$47 \quad 8$

183

2120

$69^{a}$

$60428^{\mathrm{c}}$

509

8

8

0.3

1508

$$
71^{\mathrm{c}}
$$

Ingeniero industrial

Ingeniero mecánico

Ingeniero químico

Otros ingenieros

Lic. Admón empresas

Libreros

Médicos (varias especialidades)

Odontólogos

Periodistas

Profesiones artísticas

Profesores de

$$
\text { educ. media }
$$

Publicistas

Químicos

Otras profesiones

\section{Cargos de alta dirección}

(sin especificar sector)

$204 \quad 7^{2}$

Asesores

$21 \quad 10^{\mathrm{c}}$

Directores

$\begin{array}{ll}47 & 23\end{array}$

168

Funcionarios

120

59

Jubilados

10

$0.3^{\mathrm{a}}$

Otras ocupaciones $^{\mathrm{d}}$

$129 \quad 4^{\mathrm{a}}$ 


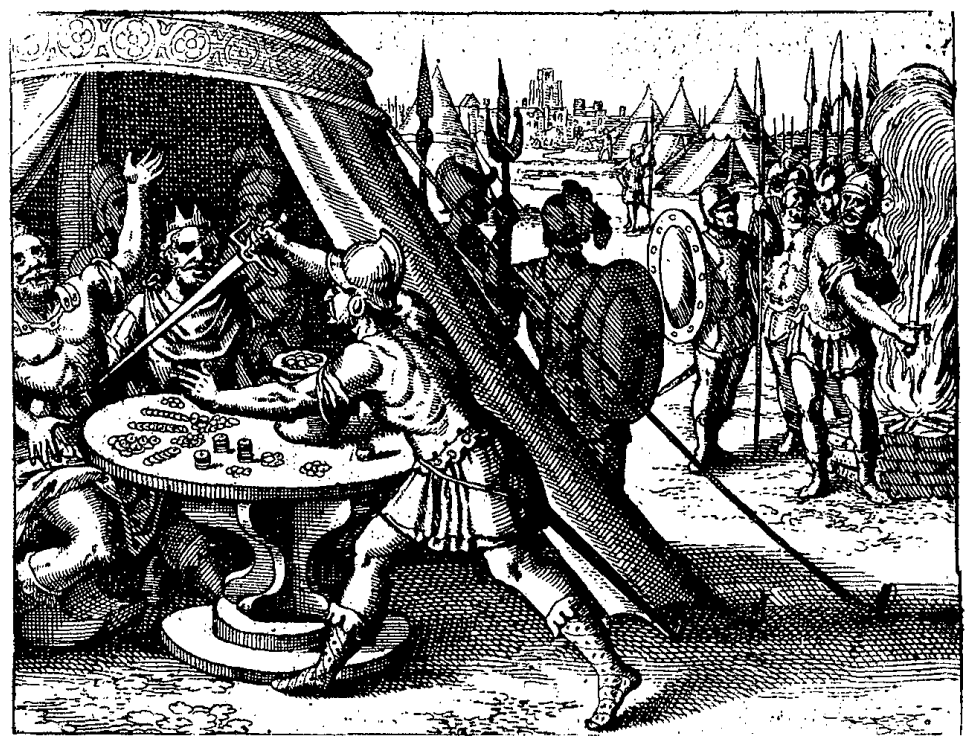

Es posible plantear, por la información antes expuesta, que en su inmen. sa mayoría este grupo se encuentra incorporado al sector servicios y, dentro de éste, el porcentaje más alto corresponde al de ocupaciones y profesiones liberales, siguen en orden de importancia las actividades comerciales $y$, al final, se encuentran las actividades financieras, las cuales, como se puede observar, no tienen la mayor importancia dentro de este sector (véanse las gráficas núms. 5 y 7 ).

Después del sector servicios, otro sector al que se encuentra integrado este grupo es al sector secundario, así lo demuestra el total de individuos registrados como industriales. Un porcentaje significativo de esta población ocupa cargos de alta dirección. Su in- tegración al sector primario es insignificante. Los datos reflejan en parte, que se trata, como dijo la señora González, de un grupo económicamente prominente, aspecto que se corrobora más adelante al mostrar las colonias de residencia del grupo.

Por otro lado, las principales profesiones y ocupaciones liberales que desempeña este grupo son las de: médico, ingeniero, abogado, contador público, arquitecto y licenciado en ad. ministración de empresas; cabe hacer notar que las profesiones de médico e ingeniero -las más numerosas por cierto-corresponden a diversas especialidades. Se trata además de profesiones rentables (véase gráfica núm. 9).

En cuanto a las actividades comerciales, aunque el Directorio no especifica 
su cargo dentro de los negocios registrados, se puede plantear que, en general, son propietarios de los comercios a los que hacen referencia, los cuales son de diversa índole (refaccionarias, gasolineras, mueblerías, abarrotes en general, zapaterías, conservas alimenticias, restaurantes, tiendas de ropa, artículos deportivos, curtidurías, librerías, embutidos, panificadoras, etc.). (Sobre el comercio, véase la gráfica núm. 8.)

Respecto a los industriales, éstos se localizan en distintas ramas del sector secundario como son: la industria de la construcción, electrónica, del acero, química, textil, del calzado y maquinaria en general, entre otras. (Al respecto, véase la gráfica núm. 6 .)

Dentro del rubro que hemos denominado cargos de alta dirección, destacan, en primer lugar, los ejecutivos y directores de empresas industriales, comerciales y turísticas, como la Casa Pedro Domecq, Empacadora Herdez, Cra. Hermanos Vázquez, Industrias La Vasconia, Almacenes El Nuevo Mundo, Cervecería Modelo, Iberia, Líneas Aéreas, tiendas de autoservicio como Gigante, Aurrerá, Ferretería Dos Leones, Galletas Marian y Cuétara, Alpura, Hotel Camino Real, Llantera Euzkadi, entre otras. En segundo lugar se encuentran los asesores, los cuales desempeñan esta actividad en distintas instituciones financieras y empresas. El menor número corresponde a los funcionarios públicos (véase gráfica núm. 10).

\section{Lugar de residencia}

Respecto a esta variable el Directorio contiene el domicilio particular de los 6541 individuos. Cabe señalar que ante la falta de homogeneidad en la denominación de los sitios de residencia registrados -en la mayoría de los casos el nombre de un mismo lugar aparece anotado de muy distinta manera o bien no corresponde a su denominación real-, fue preciso depurar esta información antes de iniciar el análisis de esta variable.

Esta población se encuentra distribuida, en primer lugar, en las 16 delegaciones que corresponden al Distrito Federal; en segundo lugar, en los distintos municipios que pertenecen al Estado de México y en un tercer lugar muy minoritario en el interior del país y en otros países.

Por el número y diversidad de colo. nias en donde se localiza este grupo, tanto en el caso del Distrito Federal como en el Estado de México, esta variable se presenta por bloques de colonias próximas unas de otras, y dentro de éstas sólo se considera a las más representativas. $^{8}$

Al Distrito Federal corresponden 3999 casos, el $61 \%$ del total, los cuales se localizan por orden de importancia, en las siguientes delegaciones.

$\begin{array}{lrr}\text { Benito JuÁrez } & 1232 & 19 \\ \begin{array}{cc}\text { Núm. 1 } \\ \text { Del Valle }\end{array} & 467 & 7\end{array}$

${ }^{8}$ Aquellos bloques que en conjunto rebasan el 1 por ciento. 
Total \%

Núm. 2

Narvarte, Letrán Valle,

Pedro Ma. Anaya, Portales

Núm. 3

Florida, Guadalupe Inn, Nápoles, Nochebuena, San José Insurgentes

Núm. 4

Álamos, Vértiz Narvarte, Viaducto Piedad

Miguel. Hidalgo

Núm. 1

Bosque de las Lomas, Lomas A Itas, Lomas Barrilaco, Lomas de Bezares, Lomas de Chapultepec, Lomas Reforma, Lomas Virreyes

Num. 2

Chapultepec Morales, Los Morales, Polanco Chapultepec, Polanco Reforma, San Miguel Chapultepec

Núm. 3

Anzures, Escandón, Granada, Irrigación, Nueva Anzures

COYOACÁN

Núm. 1

Jardines del Pedregal de San Ángel
393

229

143

1162

478

430

176
Total

174

Prado y Campestre

Churubusco

3 Núm. 3

148

2

Parque San Andrés, Romero de Terreros, Villa Coyoacán

\section{Núm. 4}

126

Coyoacán en gral., Del Carmen

18 Cuauhtemoc

409

6

216

3

Centro, Cuauhtémoc, Juárez, Santa María la Ribera

Núm. 2

110

2

Roma, Roma sur

$7 \quad$ Núm. 3

Condesa, Hipódromo de la Condesa

Gustavo A. MADERO

267

Núm. 1

208

3

4 Lindavista

Núm. 2

59

0.9

Guadalupe Tepeyac, Industrial, Tepeyac,

9 Insurgentes

3 Álvaro Obregón

Núm. 1

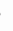

Chimalistac, Lomas de 


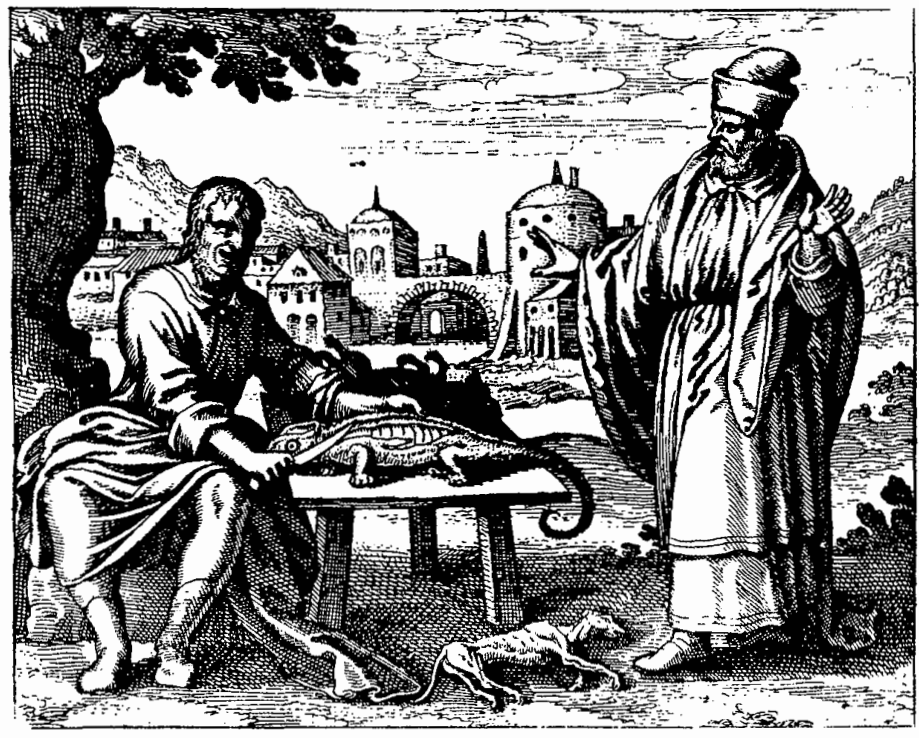

Total \% del total, los cuales se ubican fundamentalmente en distintas colonias del

San Ángel, San Ángel, San Ángel Inn

\section{Núm. 2}

Las Águilas, Olivar de los Padres, San Pedro de los Pinos

\section{TLAIPAN}

Núm. 1

Club de Golf México, Fuentes del Pedregal, Tlalpan en gral., Toriello Guerra municipio de Naucalpan, en segundo lugar en Tlalnepantla, en tercer lugar en el Estado de México, sin especificar 1 el municipio, y por último los que habitan en Atizapán de Zaragoza y Huixquilucan.

Al Estado de México, por su parte, corresponden 912 casos, es decir, $14 \%$
Núm. 2 
Núm. 3

La Herradura

Núm. 4

Bosques de Echegaray,

Rincón de Echegaray

Núm. 5

Boulevares, Jardines de San Mateo, La Florida

Núm. 6

Naucalpan en gral.

TLALNEPANTLA

Núm. 1

Valle Dorado, Vista

Hermosa

ESTADO DE MEXICO EN GRAL. $\quad 72$

ATIZA PÁN DE ZARAGOZAY HUTXQUILUCAN

Al interior del país y a otros países, corresponden únicamente 27 casos, es decir, el $0.4 \%$ del total, éstos se localizan en los siguientes lugares:

$\begin{array}{lrr} & \text { Total } & \% \\ \text { RePUBLICA MEXrcaNa } & 27 & 0.4 \\ \text { Celaya, Guanajuato } & 2 & \\ \text { Chetumal, Quintana Roo } & 2 & \\ \text { Córdoba, Veracruz } & 1 \\ \text { Cuernavaca, Morelos } & 5 & \\ \text { Guadalajara, Jalisco } & 1 \\ \text { Irapuato, Guanajuato } & 1 \\ \text { La Paz, Baja California Sur } & 1 & \end{array}$
1 San Juan del Río, Querétaro 1 Pachuca, Hidalgo 2 Silao, Guanajuato 1
1 Tequisquiapan, Querétaro 1 Tijuana, Baja California Norte

1 OTROS PAISES

$\begin{array}{lll} & \text { Bogotá, Colombia } & 1 \\ \text { España } & 4 \\ 2 & \text { Estados Unidos } & 1\end{array}$

Es necesario subrayar que el $25 \%$ 2 restante del total de referencias consignadas (6541) se distribuye en otras de-

2 legaciones, colonias del Distrito Federal, así como en otros municipios del Estado de México, distintos a los antes anotados, no considerados en este aná-

1 lisis por no ser representativos; ninguno de estos sitios de residencia en particular alcanzan siquiera el 1\% del total de casos.

Como se puede observar, esta población española se localiza básicamente en siete de las 16 delegaciones en que se divide el Distrito Federal, de las cuales destacan Benito Juárez, Miguel Hidalgo y Coyoacán. Tanto en el caso del Distrito Federal, como en el de los municipios del Estado de México, las cifras más altas corresponden siempre a colonias comúnmente habitadas por personas de medianos y altos ingresos. De este modo se confirma el planteamiento antes expuesto de que las personas de ascendencia española registradas en el Directorio conforman un grupo relevante en términos económicos y presenta un estatus de 
privilegio dentro de la estratificación social mexicana (véanse gráficas de la 11 a la 18).

\section{A MANERA DE CONCLUSIÓN}

La inmigración española en México representa en la actualidad el segundo grupo extranjero establecido en el país. ${ }^{9}$ De acuerdo con el Censo General de Población de 1980, la cifra total de españoles es de 32240 . De este modo, es evidente que el Directorio de la Colonia Española no incluye al conjunto de esta población, se ocupa únicamente del sector más distinguido en términos económicos y sociales. Esta fuente permite observar ciertas tendencias y características de una porción de esta inmigración, ya que incluye un univeso aproximado de 15000 personas de ascendencia española entre individuos registrados, sus esposas e hijos.

Una de las limitaciones de la fuente en cuestión radica en que la información carece de uniformidad. Con excepción del nombre de la persona a la que se hace referencia y de su domicilio particular, los datos contenidos en las otras variables no son homogéneos. Esta carencia deja entrever que no se encuentra debidamente actualizada, a pesar de lo dicho por la señora González en el sentido de que anualmente se coteja la información; puede ser también que a las personas no les interese o convenga proporcionar este tipo de datos.

El perfil que presenta la población

${ }^{9} \mathrm{El}$ primer lugar lo ocupa la inmigración estadunidense. española registrada en el Directorio ha sido comentado a lo largo de este trabajo, por lo que, en este apartado, sólo queda resumirlo:

Se trata de un grupo aparentemente integrado, en su inmensa mayoría, por hombres; las mujeres son minoritarias, pero es necesario hacer hincapié una vez más en que la cifra de hombres casados revela la existencia de un mayor número de mujeres, sobre las cuales desafortunadamente no es posible plantear con exactitud si se trata de españolas, porque la fuente no especifica su nacionalidad, aunque es muy factible que parte de ellas sean de origen español.

Por lo que respecta a los hombres predominan los casados, no es el caso de las mujeres sobre las cuales es de llamar la atención que 50 de las 167 registradas, es decir el $30 \%$, sean viudas y sólo el $6 \%$ estén casadas, porcen taje que también puede modificarse $s i$ se toma en cuenta nuevamente que parte de las esposas consignadas son españolas. Asimismo, tampoco deja de pasar inadvertido que en su gran mayoría $(107$ o el 64\%) no registren su estado civil.

Los datos obtenidos en la variable descendencia reflejan una tendencia, por parte de esta población, a tener una prole hasta cierto punto numerosa. Como ya se ha dicho, el promedio de hijos general de los casos que contienen esta información es de $3.18 \%$, si bien en términos particulares el porcentaje más alto corresponde a las familias integradas por dos hijos. En síntesis, los datos registrados en esta variable muestran la existencia de una importante segunda generación de individuos de ascendencia española.

Mónica Palma, Magdalena Ordóñez 
En cuanto al ámbito económico, esta población se encuentra mayoritariamente incorporada al sector servicios $y$, en menor medida, al sector industrial. Su participación en el sector primario carece de importancia. De todas las ocupaciones consignadas, definitivamente sobresalen los profesionistas, dentro de los cuales predominan los ingenieros y médicos especializados en las distintas ramas en las que se dividen estas profesiones, los abogados, arquitectos, contadores públicos y licenciados en administración. Un buen porcentaje del grupo (el $28 \%$ ) se ubica en el comercio, y en general son propietarios de los negocios registrados.

Aparte de los profesionistas y comerciantes, las otras ocupaciones más representativas son las de industrial, empresario, ejecutivo, director de empresa y asesor financiero o empresarial. Son sumamente escasos los ocupados en otras áreas de la producción o en las actividades científicas y artísticas y los ocupados como empleados y técnicos. El Directorio no registra además a ningún artesano y obrero, y sólo diez están jubilados.

Por todo lo anterior, es posible plan- tear que se trata de un grupo en edad productiva, sólidamente integrado a la economía nacional, que ejerce ocupaciones y profesiones por demás renta. bles y lucrativas, socialmente incorporado a los estratos medios y de muy altos ingresos de la sociedad mexicana; esta última característica se confirma al observar su tendencia a habitar en lugares considerados como zonas residenciales, tanto en el Distrito Federal como en el Estado de México.

En suma, aunque esta población no se compone, y a diferencia de lo dicho por la señora González, exclusivamente o mayoritariamente de hombres de negocios y altos ejecutivos, sí se trata de un grupo de españoles económica y socialmente privilegiado.

El Directorio, de este modo, cumple parcialmente con uno de los objetivos de su creación: el ser un medio de comunicación de la comunidad española en México. Sólo en parte porque, en él, no se encuentra representada toda la comunidad.

Por último, uno de los méritos de esta fuente consiste en incluir información tanto de antiguos residentes como de refugiados. 


\section{SECUENCIA

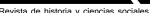

Gráfica 1. Clasificación por sexo

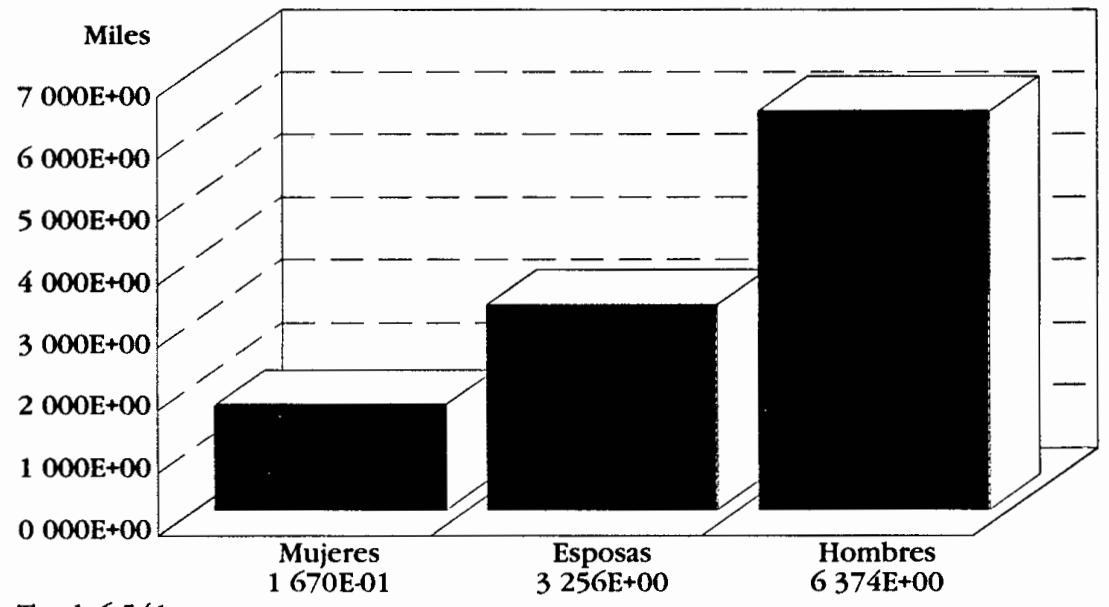

Total: 6541

Gráfica 2. Estado civil por sexo (masculino)

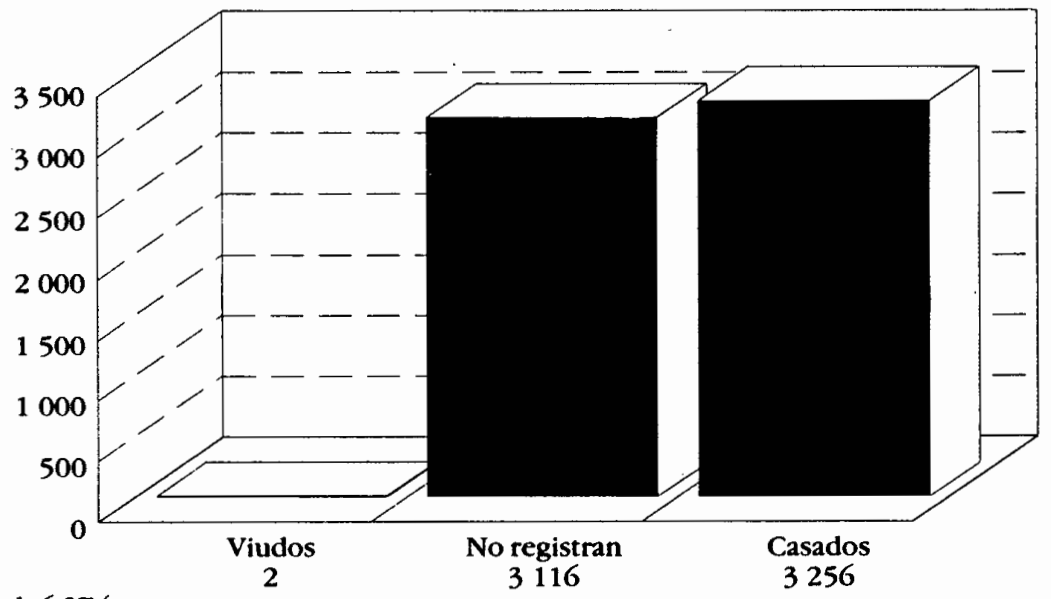

Total: 6374 
Gráfica 3. Estado civil por sexo (femenino)

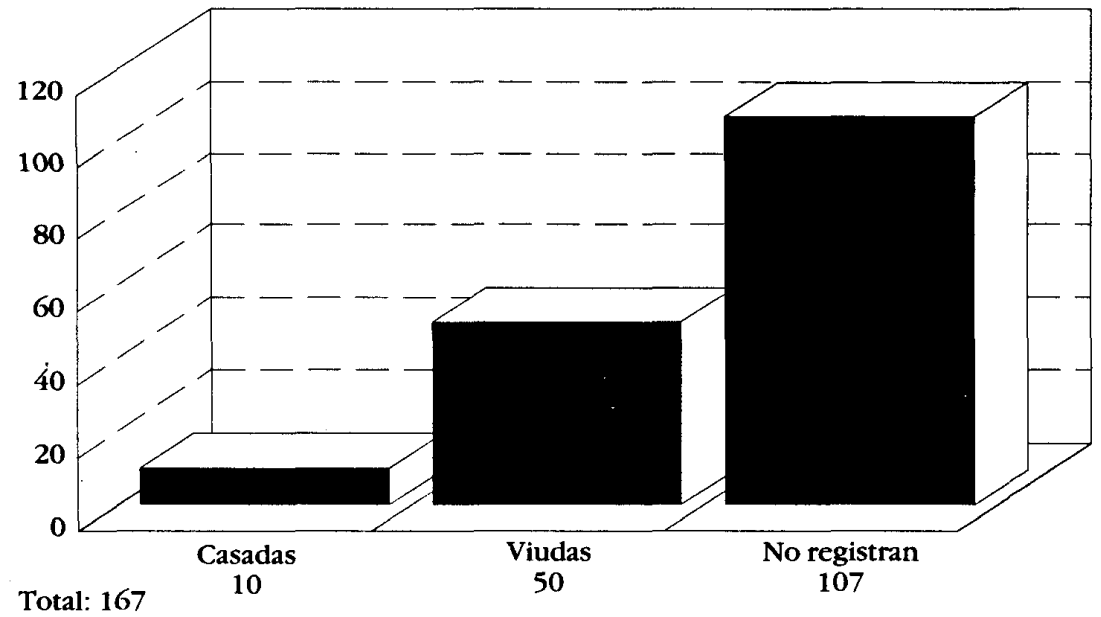

Gráfica 4. Promedio de hijos por familia

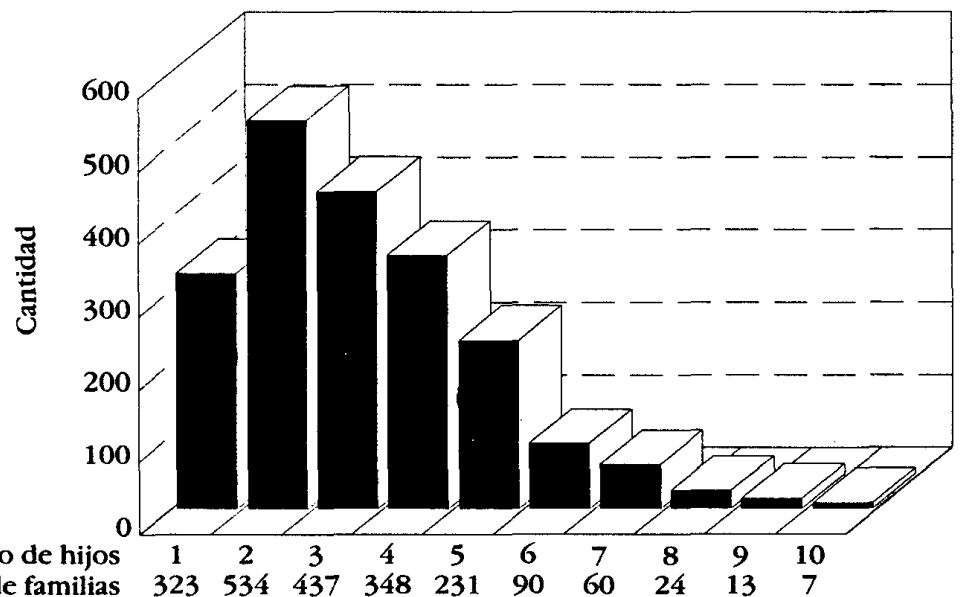

Número de hijos $\begin{array}{lllllllllll}\text { Número de familias } & 323 & 534 & 437 & 348 & 231 & 90 & 60 & 24 & 13 & 7\end{array}$

Total: 2067 
Gráfica 5. Ocupaciones y profesiones (sectores de la economía)

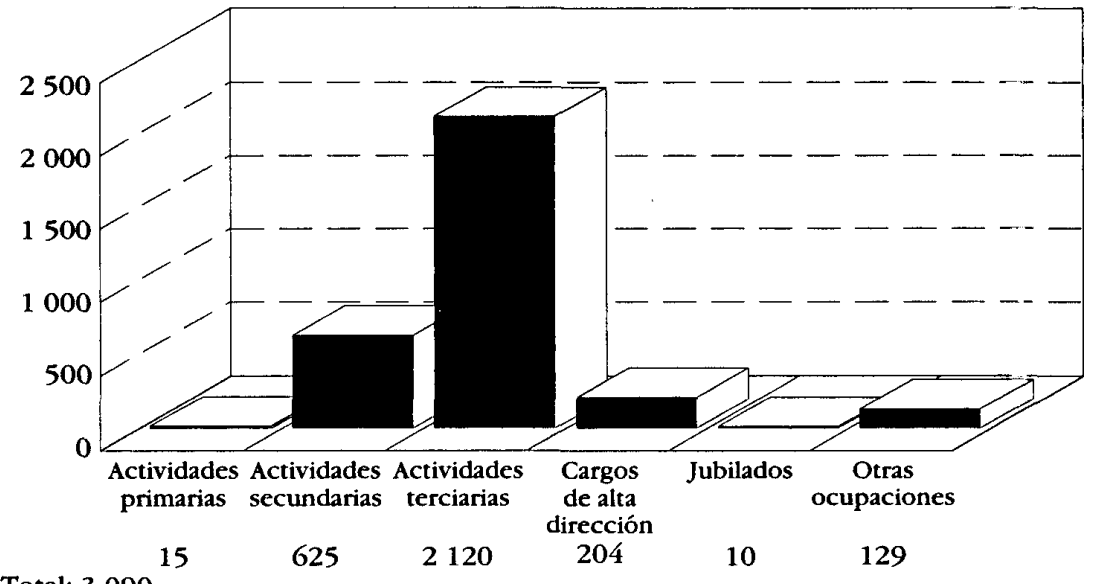

Total: 3090

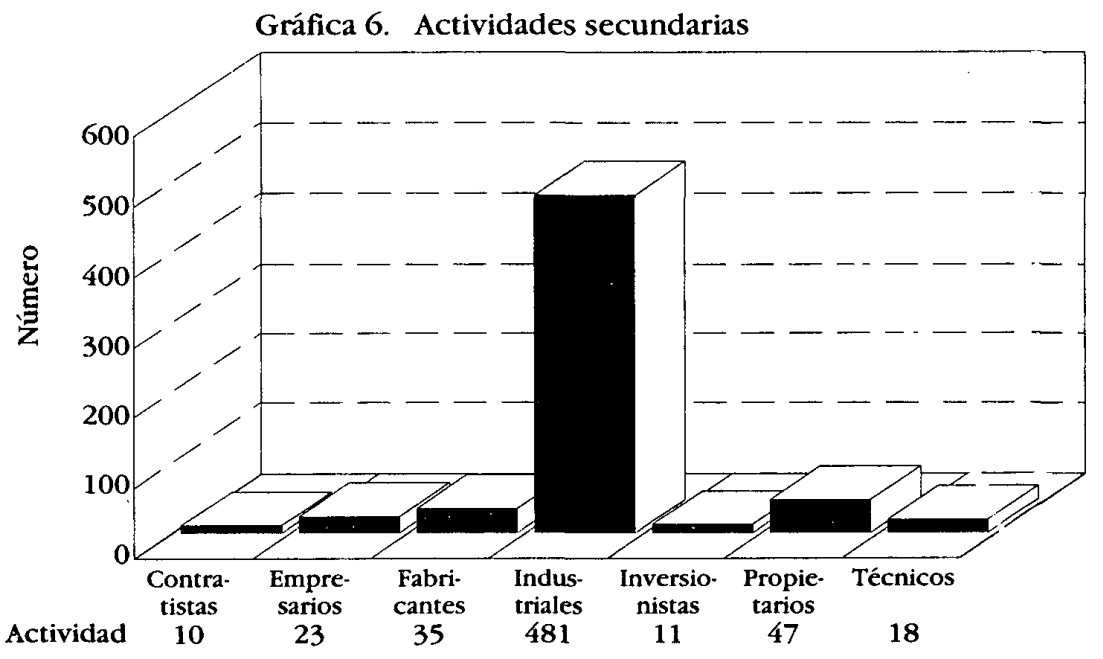

Total: 625 


\section{SECUENCIA}

\section{Gráfica 7. Actividades terciarias}

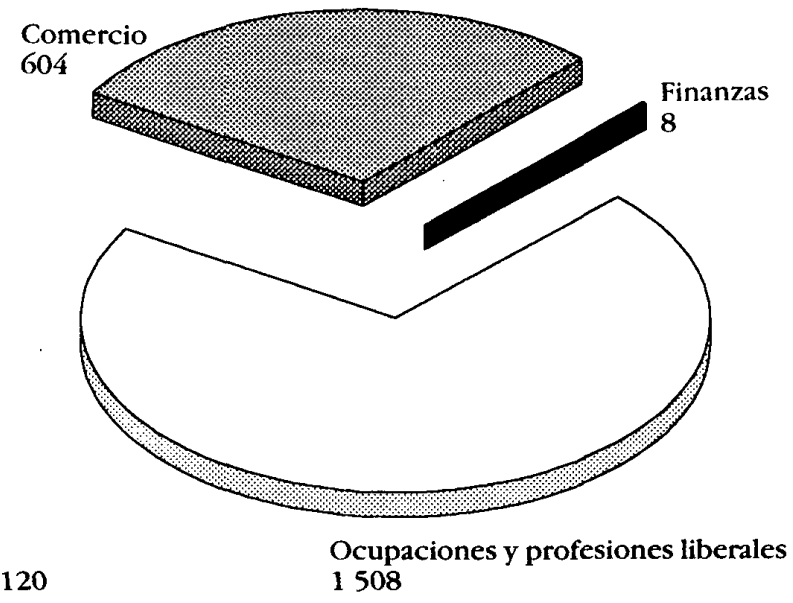

Total: 2120

$$
1508
$$

\section{Gráfica 8. Comercio}

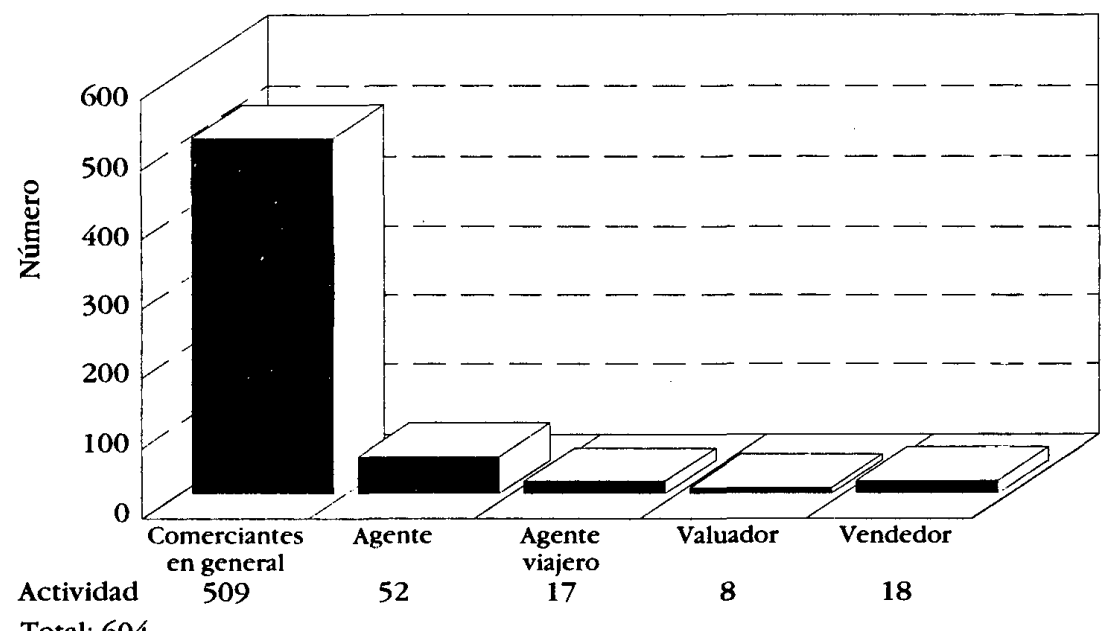

Total: 604 


\section{SECUENCIA}

\section{Gráfica 9. Ocupaciones y profesiones liberales}

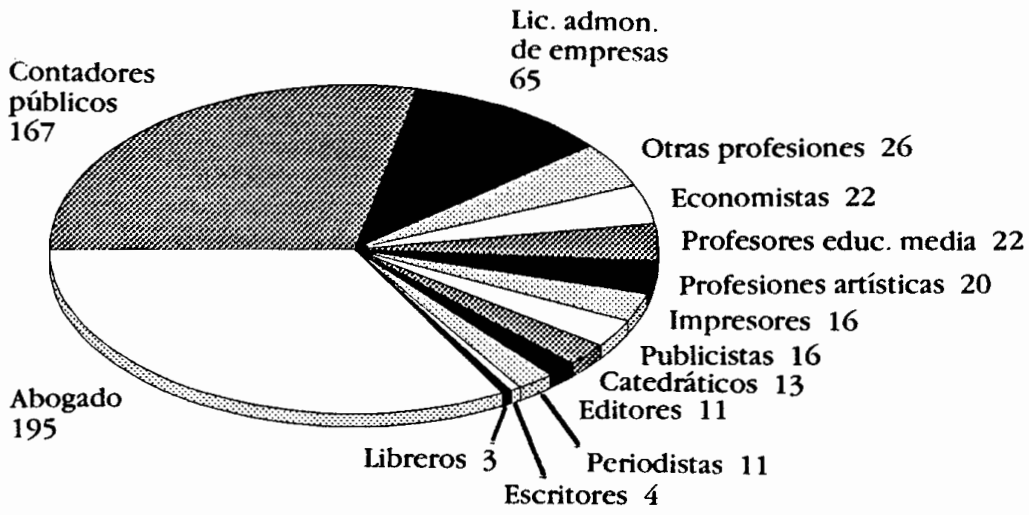

Total: 1508

Grifica 9A. Ocupaciones y profesiones liberales

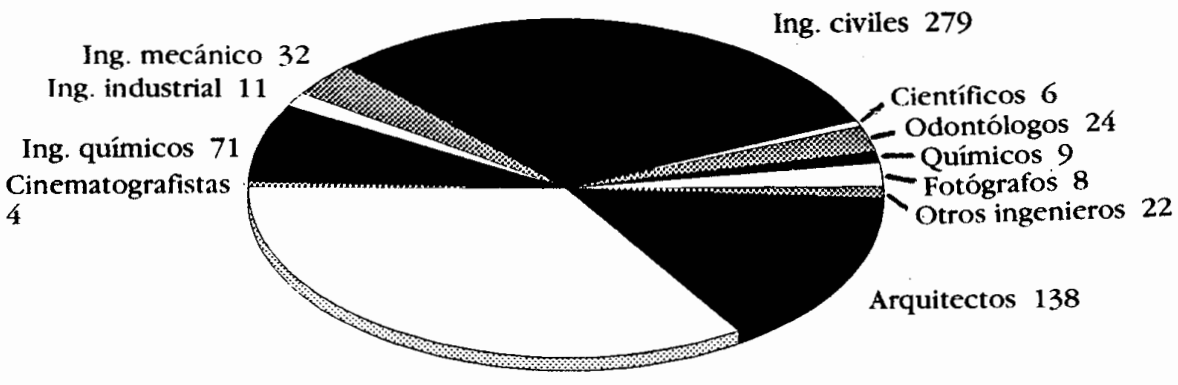

Médicos 314

Total: 1508 


\section{Gráfica 10. Cargos de alta dirección (sin especificar sector)}

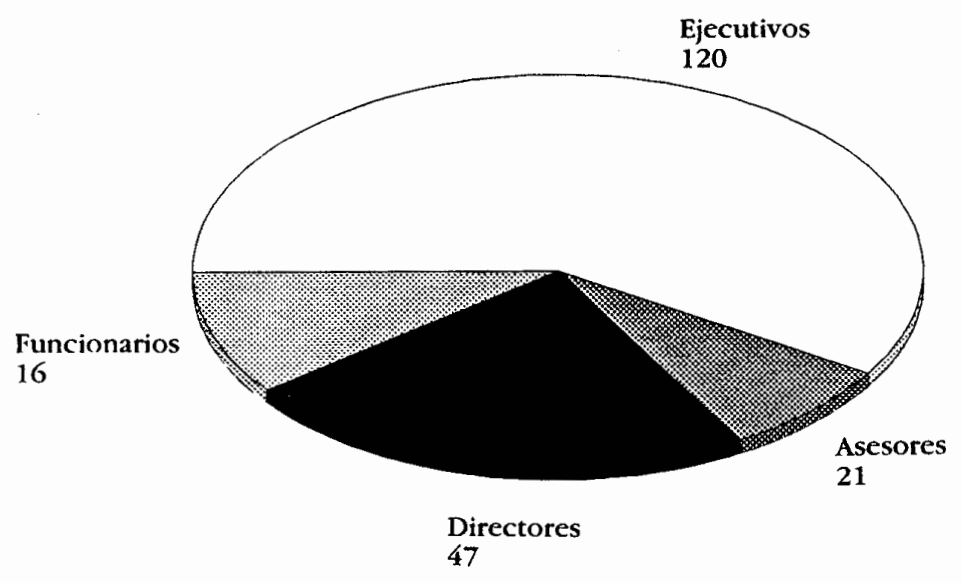

Total: 204 


\section{SECUENCIA}

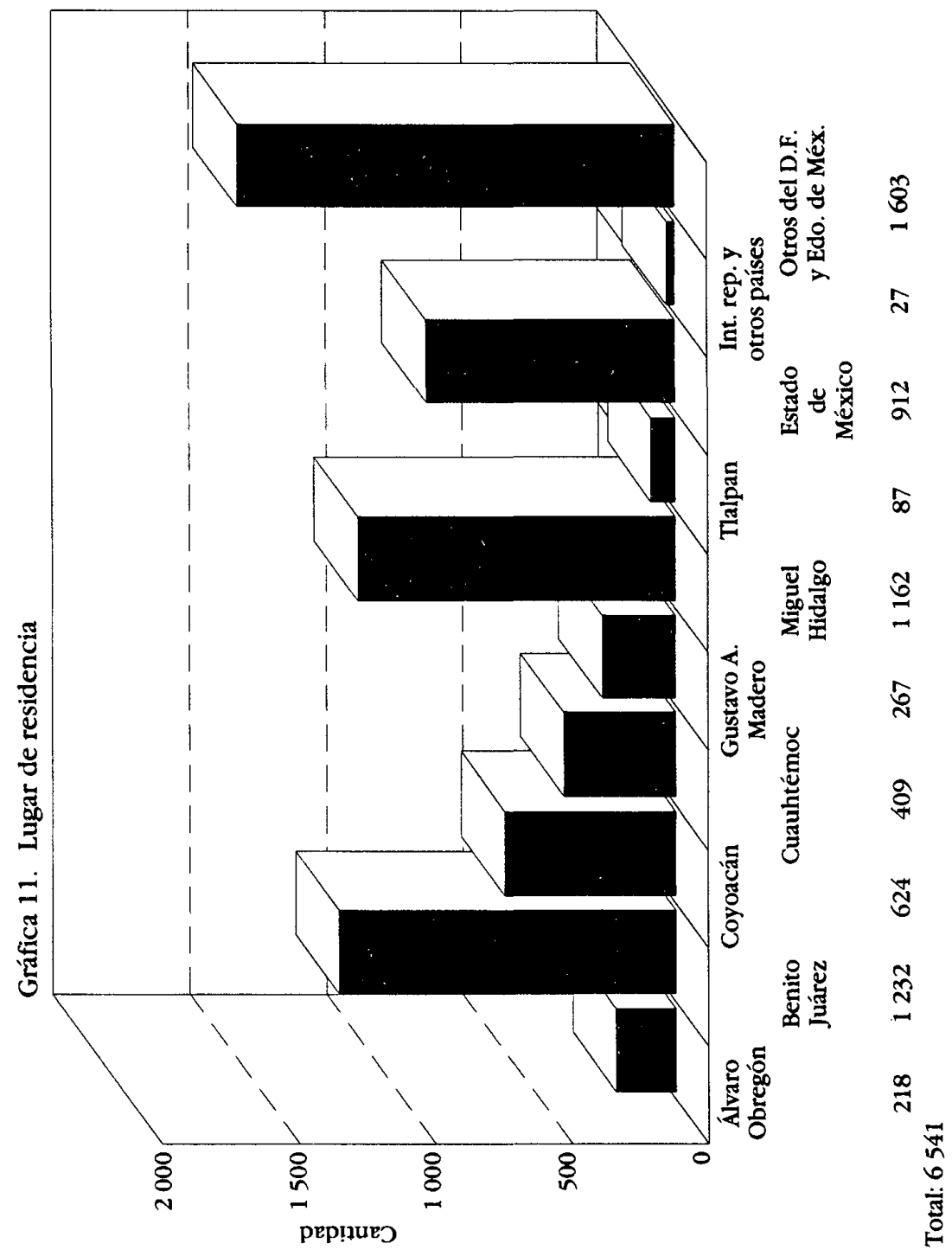




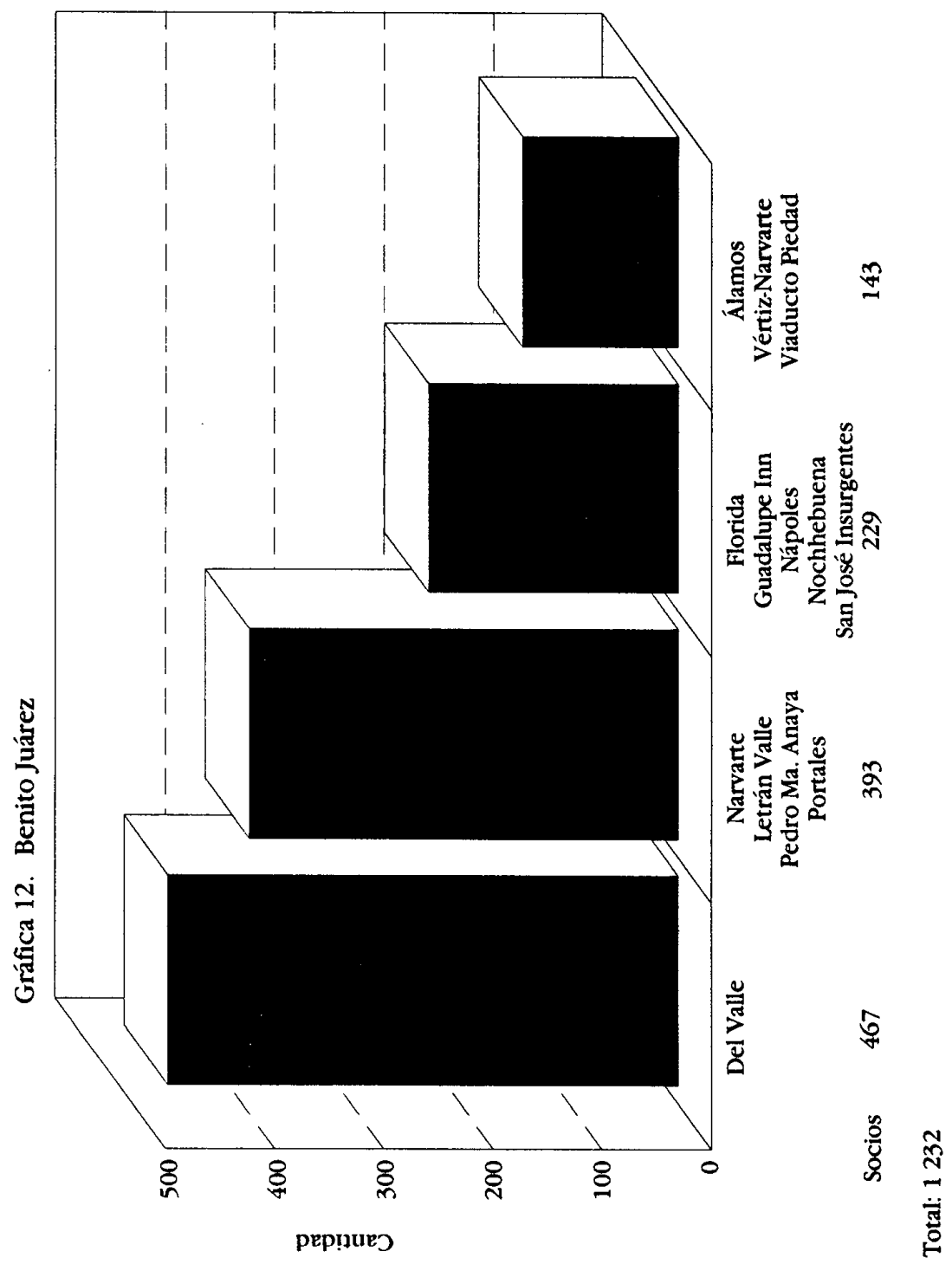




\section{SECUENCIA}

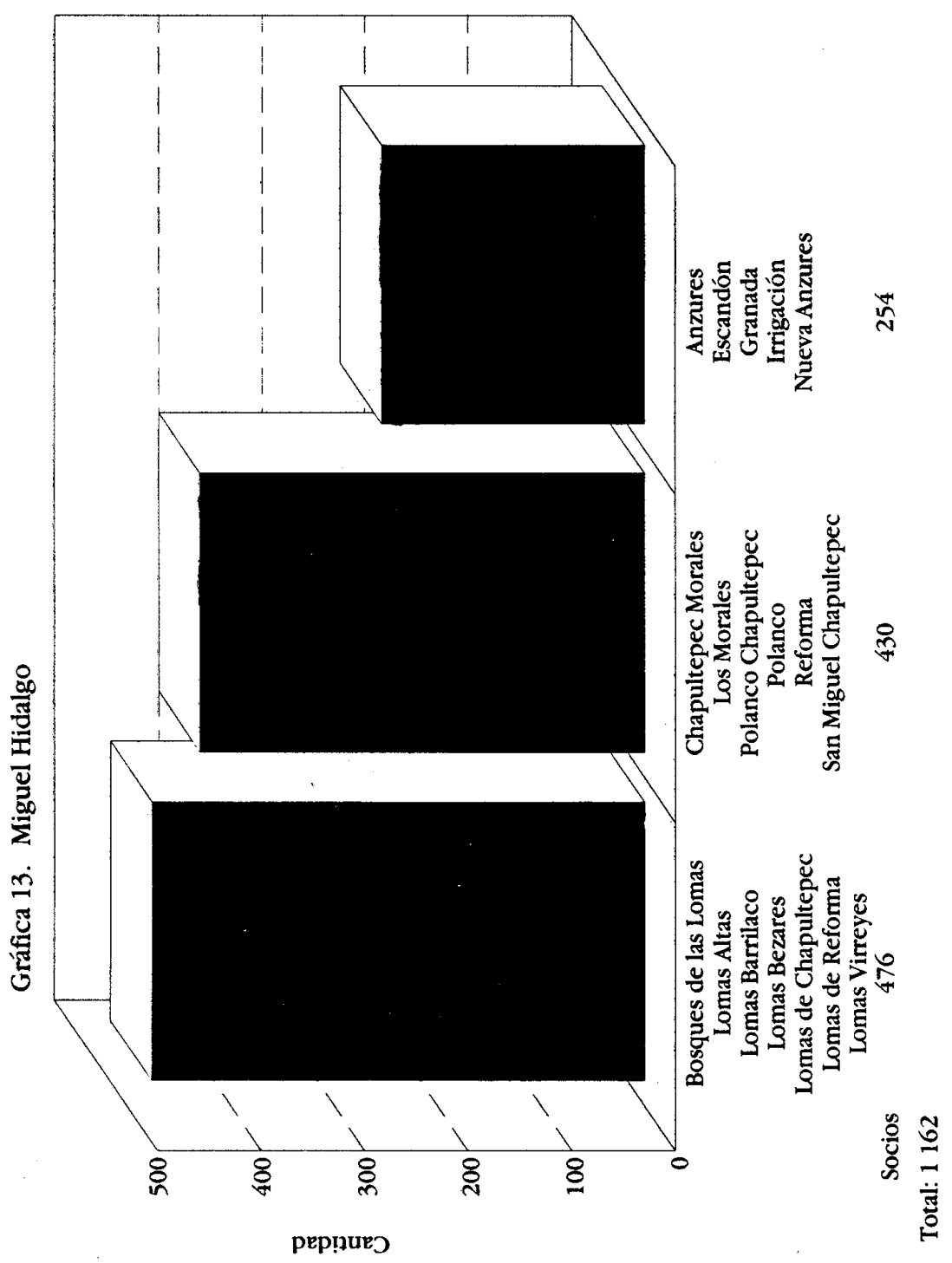




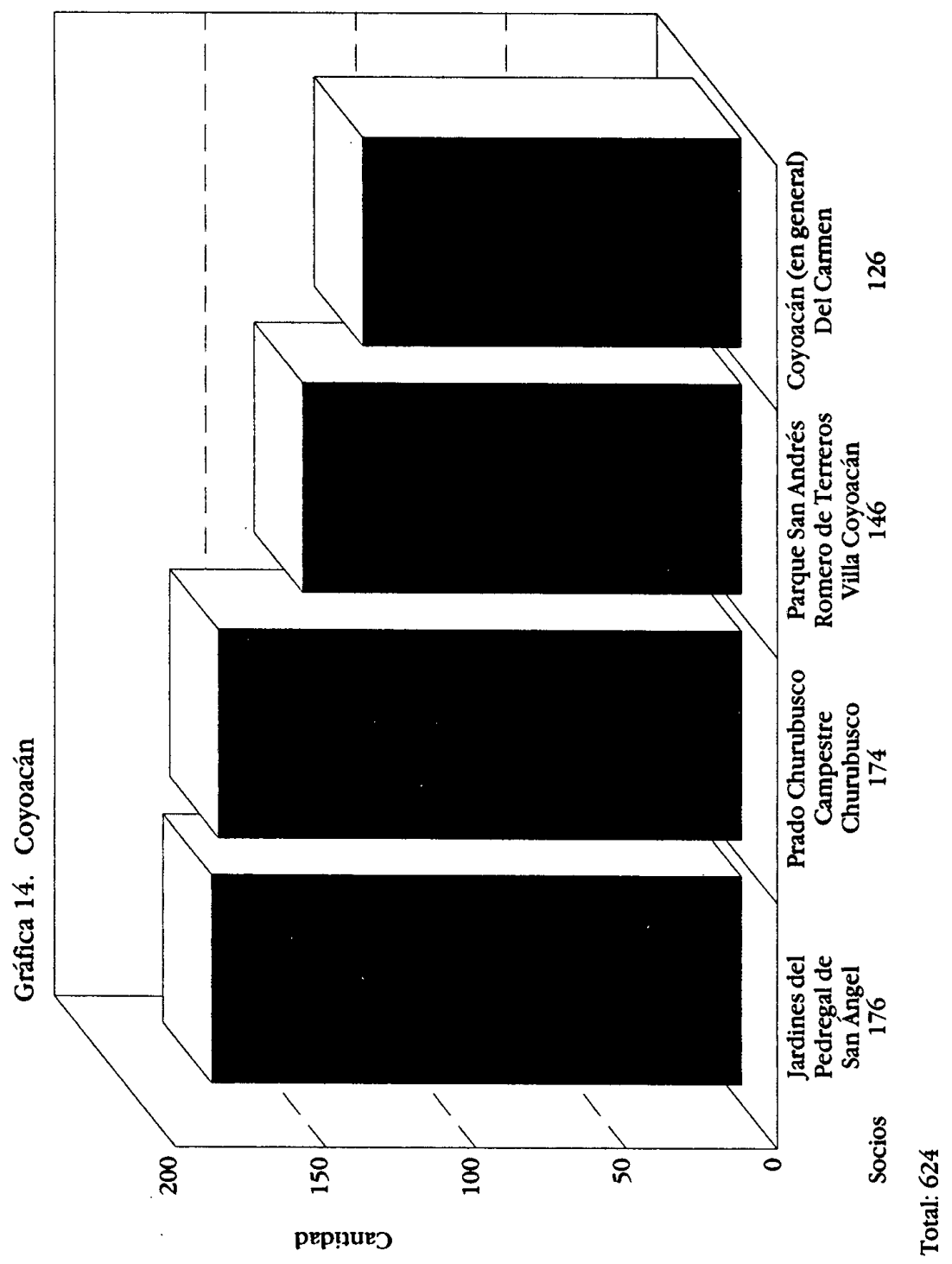




\section{SECUENCIG}

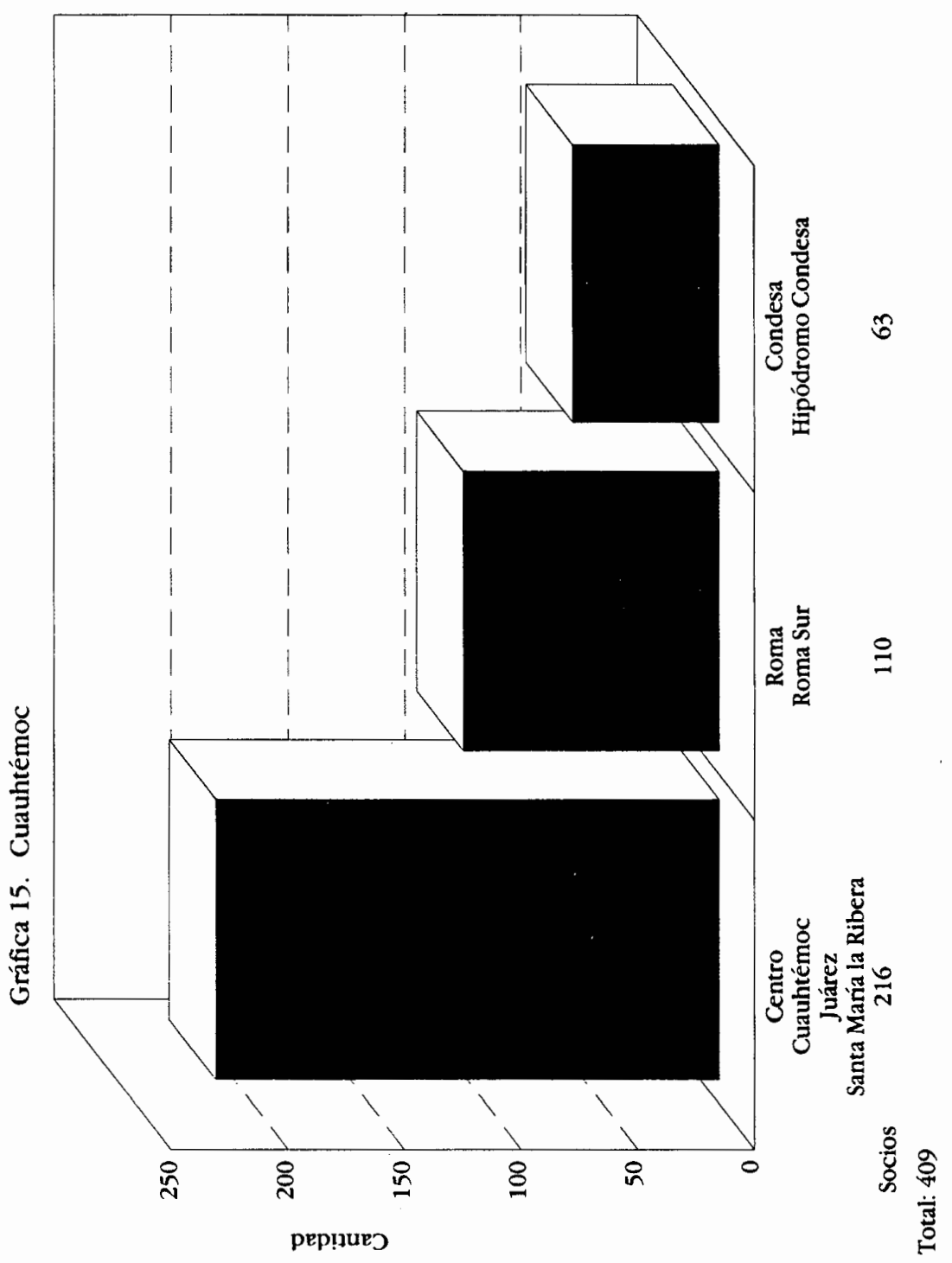




\section{SECUENCIA}

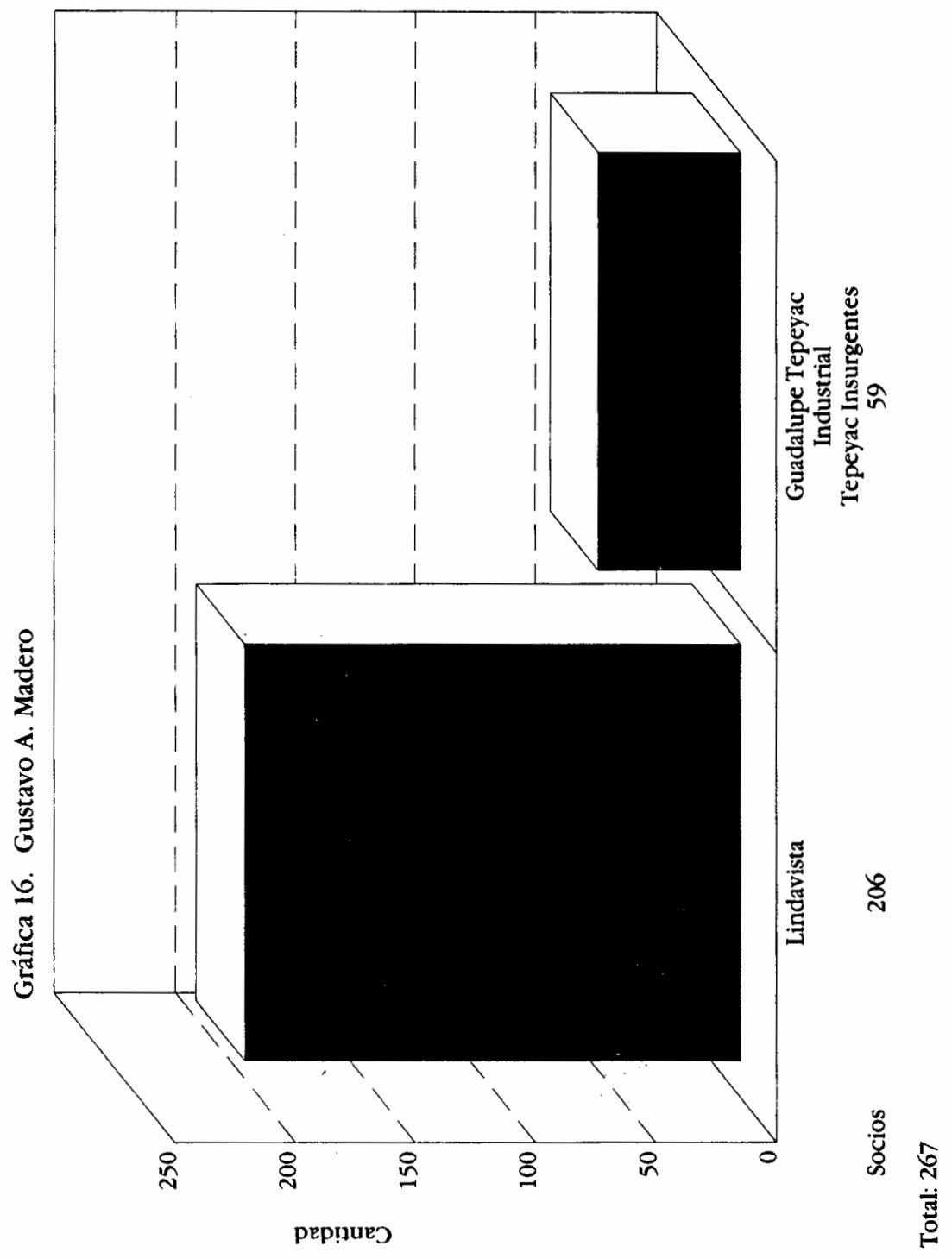




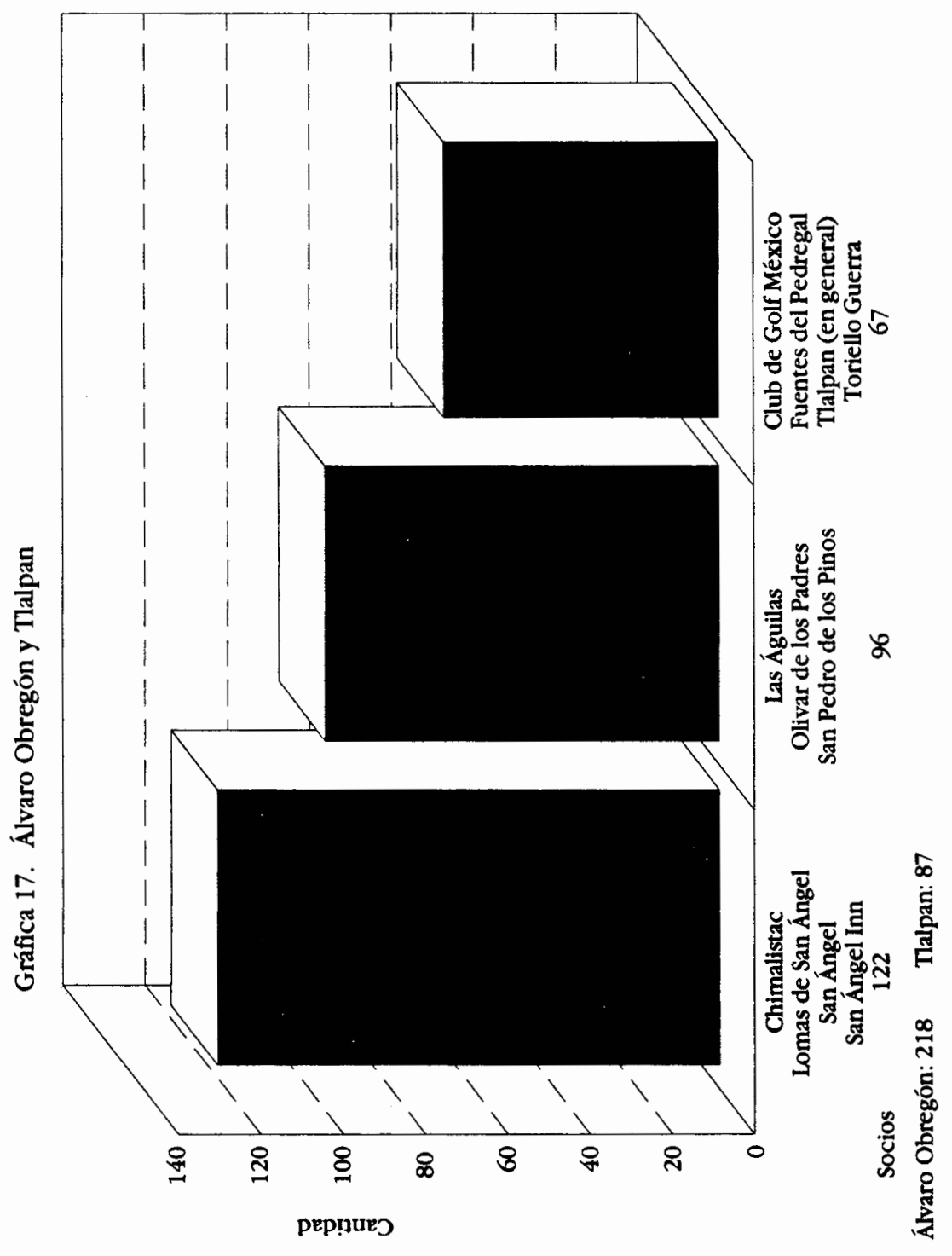




\section{SECUENCIA}

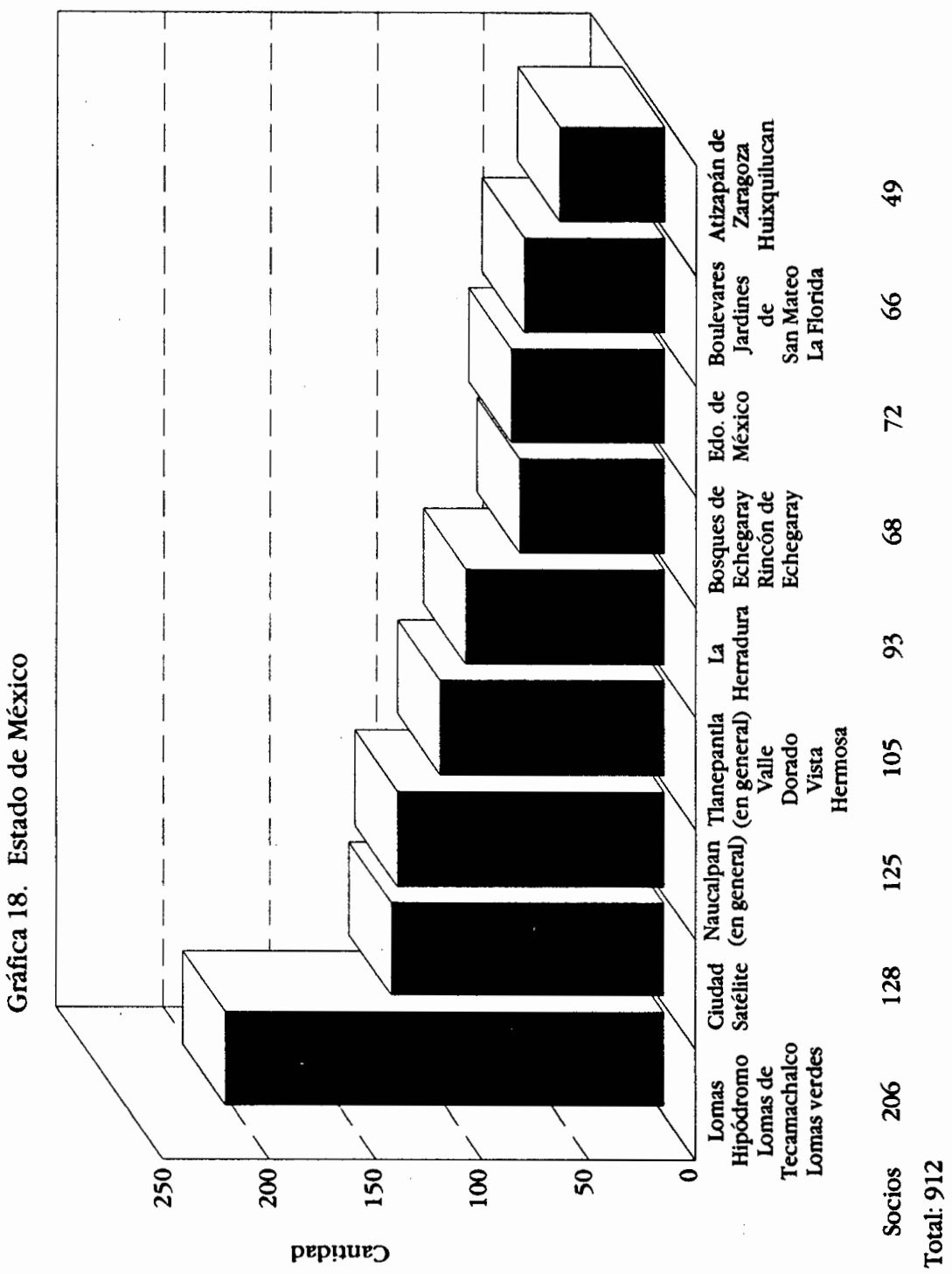




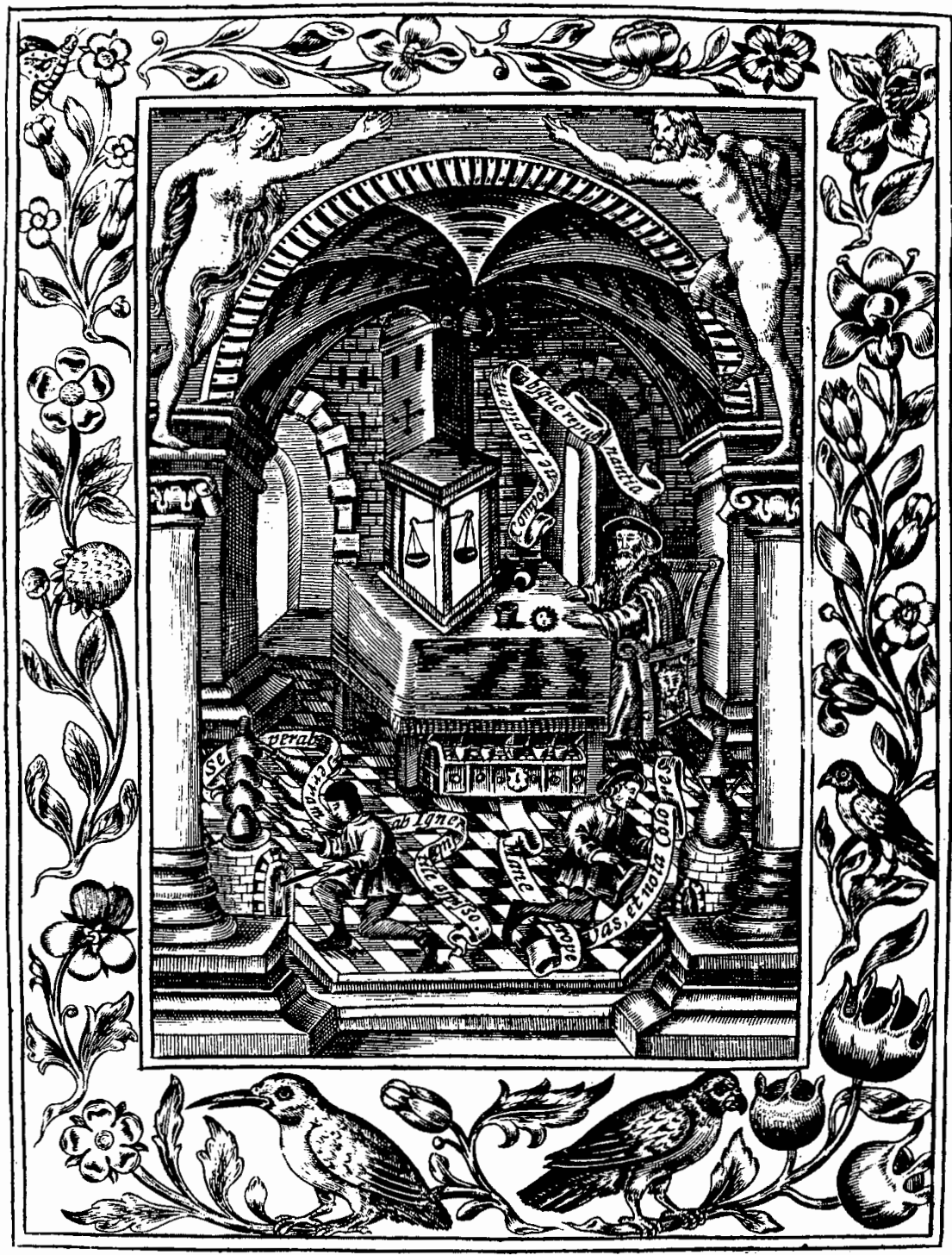

